\title{
Body mass index and annual increase of body mass index in long-term childhood cancer survivors; relationship to treatment
}

\author{
Cornelia A. J. Brouwer • Jourik A. Gietema • \\ Judith M. Vonk • W. J. E. Tissing • \\ Hendrika M. Boezen • Nynke Zwart • Aleida Postma
}

Received: 22 September 2010 / Accepted: 27 December 2010/Published online: 15 January 2011

(C) The Author(s) 2011. This article is published with open access at Springerlink.com

\begin{abstract}
Purpose Evaluation of body mass index (BMI) at final height $(\mathrm{FH})$ and annual BMI increase in adult childhood cancer survivors (CCS) after treatment with anthracyclines, platinum, and/or radiotherapy.

Methods BMI (weight/height ${ }^{2}$ ) was calculated retrospectively from diagnosis until $\mathrm{FH}$. The prevalence of underweight $\left(\mathrm{BMI}<18.5 \mathrm{~kg} / \mathrm{m}^{2}\right)$ and overweight $\left(\mathrm{BMI} \geq 25 \mathrm{~kg} / \mathrm{m}^{2}\right) /$ obesity $\left(\mathrm{BMI} \geq 30 \mathrm{~kg} / \mathrm{m}^{2}\right)$ at $\mathrm{FH}$ was compared with age-matched controls. The association between underweight/overweight at $\mathrm{FH}$ and treatment was assessed by multivariate logistic regression. Annual BMI increase after treatment was assessed by multilevel analysis. Analyses were adjusted for age and underweight/overweight at diagnosis, and age at $\mathrm{FH}$.

Results At FH the prevalence of overweight had not increased, while CCS experienced more underweight as compared to controls $(14 \%$ vs. $4 \%, P<0.001)$. Overweight at $\mathrm{FH}$ was associated with cranial/craniospinal radiotherapy (CRT; OR,
\end{abstract}

C. A. J. Brouwer · W. J. E. Tissing $\cdot$ N. Zwart · A. Postma $(\bowtie)$ Beatrix Children's Hospital, Division of Paediatric Oncology, University Medical Centre Groningen and University of Groningen,

P.O. Box 30.001, 9700 RB Groningen, the Netherlands e-mail: a.postma@bkk.umcg.nl

\section{J. A. Gietema}

Department of Medical Oncology, University Medical Centre

Groningen and University of Groningen,

P.O. Box 30.001, 9700 RB Groningen, the Netherlands

J. M. Vonk $\cdot$ H. M. Boezen

Department of Epidemiology, University Medical Centre

Groningen and University of Groningen,

P.O. Box 30.001, 9700 RB Groningen, the Netherlands
2.23; 95\% CI, 1.17-4.26) and underweight at $\mathrm{FH}$ with anthracyclines $>300 \mathrm{mg} / \mathrm{m}^{2}$ (OR, 2.84; 95\% CI, 1.33-6.06). Annual BMI increase was $+0.47(0.34-0.60) \mathrm{kg} / \mathrm{m}^{2} /$ year. In CCS, the annual BMI increase was greater in those with CRT $\geq 30$ Gy as compared with those with less or no CRT $\left(+0.15 \mathrm{~kg} / \mathrm{m}^{2} /\right.$ year $\left[0.04-0.25 \mathrm{~kg} / \mathrm{m}^{2} /\right.$ year],$\left.P=0.008\right)$ and smaller in those with a higher cumulative anthracycline dose $\left(-0.03 \mathrm{~kg} / \mathrm{m}^{2} /\right.$ year $\left[-0.05\right.$ to $-0.0005 \mathrm{~kg} / \mathrm{m}^{2} /$ year $]$ per $\left.100 \mathrm{mg} / \mathrm{m}^{2}, P=0.046\right)$.

Conclusions After treatment with anthracyclines, platinum, and/or radiotherapy, CRT-treated survivors have more overweight at $\mathrm{FH}$, and a greater annual BMI increase, while anthracycline-treated survivors have more underweight at $\mathrm{FH}$ and a lower annual BMI increase.

Keywords BMI - Body composition · Childhood cancer survivors · Longitudinal evaluation · Underweight .

Overweight

\section{Introduction}

Overweight and obesity are well-recognised late effects of childhood cancer treatment, especially in survivors of acute lymphoblastic leukaemia and brain tumours [1-3]. Because of its association with cardiovascular disease, the implications for childhood cancer survivors (CCS) are important, as many of them are at risk for treatment-related cardiac and cardiovascular disease, in particular after treatment with anthracyclines and/or mediastinal irradiation [4-8]. Recently, late cardiovascular events have also been described in longterm survivors of testicular cancer treated with platinumbased chemotherapy $[9,10]$. In addition, vascular damage is known to be induced by therapeutic irradiation $[11,12]$. It 
has been found that CCS who received irradiation of the brain and/or neck are at increased risk for stroke [13].

Abnormal body composition is considered a modifiable disorder that may play a role in intervention strategies for treatment-related cardiovascular disease; therefore, we need an understanding of the timing of its development [14].

We performed a retrospective longitudinal evaluation of body mass index (BMI) in a cohort of childhood cancer survivors who had been subjects of a study on cardiovascular disease after treatment with anthracyclines, platinum, and/or radiotherapy. The objectives of this BMI sub-study were: (1) to assess body composition, reflected by BMI after attainment of final height (FH); (2) to assess the association between over- and underweight at FH and treatment variables; and (3) to assess the annual BMI increase from end of treatment to $\mathrm{FH}$ and its association with treatment variables.

\section{Patients and methods}

Study participants and data

Participants were included within the scope of a single-centre study on cardiovascular disease and cardiovascular risk factors in adult CCS, initiated in 2004, with the following eligibility criteria: (1) diagnosis between 1976 and 1999 and at least 5 years off-treatment; (2) treatment with potential cardiovascular toxicity (anthracyclines, platinum, and/or radiotherapy (RT) of head, neck, spine, or trunk); (3) age at diagnosis $\leq 20$ years; and (4) no pre-existent cardiovascular disease and/or Down syndrome. Eligibility for the analysis of BMI was limited to those participants for whom the following data were available: weight and height at the end of treatment and at FH. Annual BMI increase was assessed if at least three BMI calculations were available throughout a follow-up period of 3 years or more before attainment of FH. If patients had been treated for a relapse, the date of termination of the last treatment was considered as end of treatment. Some survivors had suffered from several relapses and had prolonged intervals between treatments; in these patients the positive effects on BMI of prolonged treatment-free intervals and the negative effects of subsequent treatment periods could not be discerned. Therefore, patients for whom all treatments had covered 5 years or more were excluded from the BMI analysis. CCS with a relapse after 5 years or a secondary tumour were censored until 1 year before the occurrence of the late relapse or secondary tumour.

\section{Methods}

Height and weight at diagnosis, at completion of treatment, at several time points post-treatment and at FH were collected retrospectively from the medical records. BMI was calculated using the formula: weight/height ${ }^{2}\left(\mathrm{~kg} / \mathrm{m}^{2}\right)$. For adults (age $\geq$ 18 years), underweight was defined as a $\mathrm{BMI}<18.5 \mathrm{~kg} / \mathrm{m}^{2}$, overweight as a $B M I \geq 25 \mathrm{~kg} / \mathrm{m}^{2}$, and obesity as a $\mathrm{BMI} \geq 30 \mathrm{~kg} /$ $\mathrm{m}^{2}$. In children (age $<18$ years), BMI reference values of underweight, overweight, and obesity, as previously published $[15,16]$, were used. Final height $(\mathrm{FH})$ was defined as the standing height reached when height had increased less than $1.5 \mathrm{~cm}$ in two consecutive years of measurement [17]. If more than one BMI calculation was available after $\mathrm{FH}$, we used the first one after 5 years post-treatment.

The prevalence of underweight, overweight, and obesity at $\mathrm{FH}$ in the survivors was compared with the prevalence of underweight, overweight, and obesity in age- and sexmatched participants of a prospective cohort study of 3,162 newborn babies (date of birth 1975-1978). These individuals were followed for 18-22 years to identify perinatal risk factors for the development of hyperresponsiveness, lung function, and atopy. A random sample of 590 of these individuals had assessment of height and weight at median age 21.3 years (range, 19.7-23.4 years). The rationale for this particular control group was that its participants and the subjects of our study group originated from the same geographical region, had the same socioeconomic background and were more or less contemporary with comparable demographics $[18,19]$.

\section{Diagnosis}

Given the extended time period when the cancer in our cohort was diagnosed (1976-1999), treatment by diagnosis had been administered according to many different protocols and consequently has been very heterogeneous. For instance, the leukaemia diagnostic group includes patients with and without cranial irradiation, as does the brain tumour diagnostic group. Therefore we considered it not appropriate to evaluate the association between BMI status and diagnosis, but to focus on the association of BMI status and treatment variables.

\section{Treatment variables}

Because of the assumed late cardiac and vascular toxic effects, the chemotherapy categories that were examined were (1) anthracycline-based (doxorubicin, daunorubicin) combination chemotherapy, and (2) platinum-based (cisplatin, carboplatin) combination chemotherapy. The radiotherapy fields that were considered were (1) cranial/craniospinal RT (CRT), (2) chest/neck RT, including mantle field, mediastinum, total lung, neck and/or spine, (3) abdominal RT, including abdomen, pelvic and/or spine, and (4) total body irradiation (TBI). Given the time period when the cancer was diagnosed in our cohort (1976-1999), individual dosimetry on cranial structures was not available. Therefore, CRT dose was subdivided into $<30$ Gy and $\geq 30$ Gy. 
Additional variables

Additional variables that could impact the development of underweight or overweight in CCS are treatment intensity, chronic health conditions (e.g. renal dysfunction), cardiovascular disease, and family history of obesity/overweight. Therefore we retrospectively recorded the numbers of participants with (1) neutropenic periods with fever as an expression of treatment intensity, (2) glomerular filtration rate $(\mathrm{GFR})<70 \mathrm{ml} / \mathrm{min}$ as an expression of renal function, (3) shortening fraction (SF) $<29 \%$ and NYHA DC class 2 or more as an expression of cardiovascular disease, and (4) Karnovsky score $\leq 80 \%$ as an expression of general health status.

Data analysis and statistics

Statistical analyses were performed using SPSS Inc. version 14. For descriptive analyses, non-parametric tests (Mann-Whitney and Wilcoxon tests) and median (range) were used, since the parameters had a non-Gaussian distribution. The prevalence of underweight, overweight, and obesity at FH were compared with the reference population. Since the numbers of survivors with obesity were small, survivors with obesity and with overweight were analysed as one group. The primary outcome measurements were underweight and overweight at $\mathrm{FH}$. Univariate analysis was performed to compare treatment variables and additional variables among the survivors with normal weight, underweight, and overweight at $\mathrm{FH}$. Logistic regression analyses were used to assess the association between the dependent variables overweight, normal weight, and underweight at $\mathrm{FH}$, and the treatment variables. The treatment variables were tested in separate models with adjustment for possible confounders, that is, age at diagnosis, gender, age at BMI measurement at $\mathrm{FH}$, duration of cancer treatment, and underweight and overweight at diagnosis. Since several studies have shown different outcomes by gender $[1,20]$, the possible effect modification by gender was investigated by introducing an interaction variable between gender and the treatment variables in the regression analysis. BMI at completion of treatment and the annual BMI increase afterwards until FH were assessed in association with the treatment variables using multilevel analyses [21]. Two-sided $p$ values $\leq 0.05$ were considered significant.

\section{Results}

Of 1,375 (male/female [M/F] ratio, 1:3) newly diagnosed childhood cancer patients between 1976 and 1999, 985 $(\mathrm{M} / \mathrm{F}$ ratio, 1:3) survived $\geq 5$ years after diagnosis.
Diagnoses at first presentation and at 5 years survival were : leukemia $33,4 \%$ and $33,6 \%$; brain tumours $21,3 \%$ and $20,1 \%$; sarcomas $15,8 \%$ and $14,2 \%$; malignant lymphomas $13,6 \%$ and $16,4 \%$; blastomas (nefroblastoma, neuroblastoma, hepatoblastoma) $12,6 \%$ and $4,4 \%$; germ cell tumours $2,5 \%$ and $3 \%$; other $0,6 \%$ and $0,4 \%$. Of these 985 5-year survivors, 467 met the eligibility criteria for the study on cardiovascular disease and cardiovascular risk factors in adult CCS as described above and 377/ 467 CCS fulfilled the inclusion criteria for the BMI study (M/F 1,2). Of these 377 survivors who were eligible for the BMI study, sufficient data (e.g. three or more BMIs covering a follow-up period of three or more years, see Methods section) for analysis of annual BMI increase were available in 299 survivors (Fig. 1). Participants' characteristics are summarised in Table 1. The median (range) age at diagnosis was 9.3 (0.0-20.5) years and at the time of the first available BMI assessment after attainment of $\mathrm{FH}$ at $\geq 5$ years post-treatment it was $20.0(12.7-42.7)$ years.

\section{Prevalence of underweight and overweight at FH}

The prevalence of overweight (19\% [73/377] vs. 22\% [128/ $590] ; P=0.384)$ and obesity $(5 \%[17 / 377]$ vs. $5 \%[27 / 590]$; $P=0.961)$ in the CCS were comparable to those in the reference population [18, 19], whereas the prevalence of underweight was higher in the CCS (14\% [53/377] vs. 4\% [25/ 590]; $P<0.001)$. If the CCS were analysed without those with limb amputations, the results were not statistically different.

Underweight and overweight at $\mathrm{FH}$ and treatment variables

The characteristics of the CCS with overweight $(n=73)$ were compared with those with underweight at FH $(n=53)$ and those with normal weight $(n=251$; Table 1$)$. Survivors with overweight at $\mathrm{FH}$ were more often overweight at diagnosis compared to CCS with underweight at FH (15/67 vs. $1 / 48 ; p=0.002)$ and had been treated more often with CRT (40/73 vs. $13 / 53 ; p=0.001)$. CCS with underweight at $\mathrm{FH}$ were underweight more often at diagnosis as compared to those with overweight at FH (28/48 vs. $10 / 67 ; p<0.001)$, had received a higher cumulative anthracycline dose (183 vs. $\left.125 \mathrm{mg} / \mathrm{m}^{2} ; p=0.036\right)$, and had been treated more often with TBI $(8 / 53$ vs. $2 / 73 ; p=0.017)$.

Overweight at FH From the potential confounders, overweight at diagnosis (odds ratio [OR] 21.13; 95\% confidence interval [CI] 6.40-69.78; $P<0.001)$, underweight at diagnosis (OR, 0.33; 95\% CI, 0.15-0.72; $P=0.006)$, and age at BMI measurement (OR, 1.14; 95\% CI, 1.06-1.22; $P<0.001)$ were associated with overweight at $\mathrm{FH}$. There was no association with duration of treatment. In the adjusted models (including adjustment for overweight at diagnosis), 
Fig. 1 In- and exclusion of childhood cancer survivors who survived $\geq 5$ years post-diagnosis

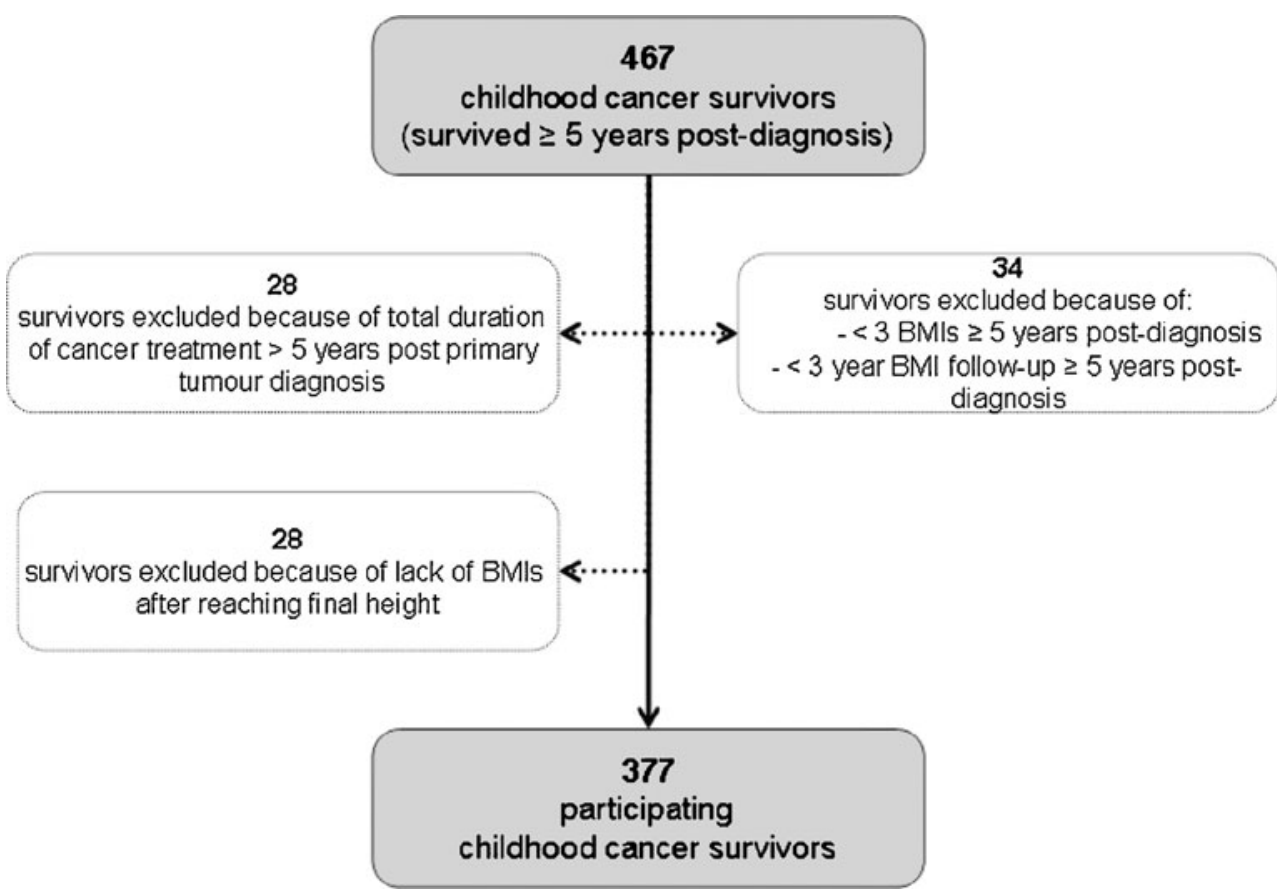

overweight at FH was associated with CRT, especially if CRT dose was $\geq 30$ Gy (Table 2). Simultaneous inclusion of CRT, TBI, and cumulative anthracycline dose $>300 \mathrm{mg} / \mathrm{m}^{2}$ in one model showed that overweight at $\mathrm{FH}$ was associated with CRT (OR, 2.27; 95\% CI, 1.13-4.55).

Underweight at FH From the potential confounders described in the Methods section (paragraph data analysis and statistics), underweight at diagnosis was associated with underweight at FH (OR, 3.69; 95\% CI, 1.91-7.09; $P<0.001)$. There was no association with duration of treatment. In the adjusted models (including adjustment for underweight at diagnosis), underweight at FH was associated with TBI, CRT, and cumulative anthracycline dose, especially if anthracycline dose was $>300 \mathrm{mg} / \mathrm{m}^{2}$ (Table 2). Simultaneous inclusion of TBI, CRT, and cumulative anthracycline dose $>$ $300 \mathrm{mg} / \mathrm{m}^{2}$ in one model showed that underweight at $\mathrm{FH}$ was associated with cumulative anthracycline dose $>300 \mathrm{mg} / \mathrm{m}^{2}$ (OR, 2.28; 95\% CI, 1.02-5.09; Table 2).

The introduction of interaction variables between gender and the treatment variables showed no significant difference between males and females with respect to the effect of the treatment variables on the prevalence of overweight and underweight at $\mathrm{FH}$.

Underweight and overweight at FH and additional variables

Data on additional variables were missing in a considerable number of subjects. The number of CCS with at least one neutropenic period with fever was 159 out of 371 evaluable subjects; 3 out of 254 evaluable subjects had GFR $<70 \mathrm{ml} /$ min; 89 out of 246 evaluable subjects had $\mathrm{SF}<29 \%$; 10 out of 254 evaluable subjects had NYHA DC class 2 and none had class 3; 4 out of 254 evaluable subjects had Karnovsky score $\leq 80 \%$; 86 out of 257 evaluable subjects had a family history of overweight/obesity. None of these additional variables showed a significant association with overweight/ underweight at $\mathrm{FH}$.

BMI increase post-treatment in association with treatment variables

Of the 377 survivors that were eligible for the BMI study sufficient data (see Methods section) for analysis of annual BMI increase were available in 299 (79\%). If adjusted for age, underweight and overweight at diagnosis, and gender, BMI at completion of treatment was associated with CRT (estimated BMI [Est.], $+0.59 \mathrm{~kg} / \mathrm{m}^{2}$ compared with non-CRT-treated survivors; Table 3). The annual BMI increase post-treatment until FH showed an estimated BMI increase of $+0.47 \mathrm{~kg} / \mathrm{m}^{2} /$ year $\left(0.34-0.60 \mathrm{~kg} / \mathrm{m}^{2} /\right.$ year $)$ for the entire study population. If adjusted for age, underweight and overweight at diagnosis, and gender, there was an inverse association of annual BMI increase with cumulative anthracycline dose (Est., $-0.03 \mathrm{~kg} / \mathrm{m}^{2} /$ year per $100 \mathrm{mg} / \mathrm{m}^{2}$; Table 3). Annual BMI increase in CCS with and without CRT was not significantly different ( $P=0.09$; Table 3$)$. Within the group of CCS with CRT, those who received 30 Gy or more had a greater annual BMI increase compared to those who received a lower dose or no CRT (Est., $+0.15 \mathrm{~kg} / \mathrm{m}^{2} /$ year; 95\% CI, 0.04-0.25; $P=0.008$; Table 3). 
Table 1 Characteristics of participants with normal weight, underweight, and overweight at FH; relationship to treatment variables

\begin{tabular}{|c|c|c|c|c|c|}
\hline & Total & Underweight & Normal weight & Overweight & $\begin{array}{l}p \text { value underweight vs. } \\
\text { overweight }\end{array}$ \\
\hline Number & 377 & 53 & 251 & 73 & \\
\hline Male/female & $209 / 168$ & $31 / 22$ & $140 / 111$ & $38 / 35$ & 0.47 \\
\hline Age at diagnosis (years) ${ }^{\mathrm{a}}$ & $9.3(0.0-20.5)$ & $9.5(0.0-19.5)$ & $9.4(0.4-20.5)$ & $8.0(1.1-20.1)$ & 0.89 \\
\hline $\begin{array}{l}\text { Age at first BMI available } \\
\text { after FH (years) }{ }^{\mathrm{a}}\end{array}$ & $20(12.7-42.7)$ & $19.7(15.6-28.4)$ & $20.0(12.7-42.7)$ & $20.0(12.8-41.7)$ & 0.07 \\
\hline $\begin{array}{l}\text { Follow-up post-treatment } \\
\text { at } \mathrm{FH}(\text { years })^{\mathrm{a}}\end{array}$ & $8.4(5.0-28.0)$ & $8.5(5.0-23.5)$ & $7.9(5.0-25.2)$ & $10.5(5.0-28.0)$ & 0.10 \\
\hline \multicolumn{6}{|l|}{ Diagnoses } \\
\hline Leukaemia & 151 & 17 & 97 & 37 & \\
\hline Brain tumour & 47 & 4 & 30 & 13 & \\
\hline Sarcoma & 70 & 16 & 46 & 8 & \\
\hline Malignant lymphoma & 75 & 8 & 55 & 12 & \\
\hline Blastoma & 28 & 8 & 18 & 2 & \\
\hline Germ cell tumour & 6 & 0 & 5 & 1 & \\
\hline \multicolumn{6}{|l|}{ Treatment variables } \\
\hline Anthracyclines ${ }^{\mathrm{b}}$ & 264 & 39 & 180 & 45 & 0.16 \\
\hline $\begin{array}{l}\text { Cumulative dose } \\
\text { anthracyclines } \mathrm{mg} / \mathrm{m}^{2 \mathrm{a}}\end{array}$ & & $183(0-640)$ & $160(0-600)$ & $125(0-600)$ & 0.04 \\
\hline Anthracyclines $>300 \mathrm{mg} / \mathrm{m}^{2 b}$ & 67 & 18 & 38 & 11 & 0.01 \\
\hline Platinum $^{\mathrm{b}}$ & 32 & 6 & 21 & 5 & $0.53^{\mathrm{c}}$ \\
\hline $\mathrm{Cranial}_{\text {/craniospinal irradiation }}{ }^{\mathrm{b}}$ & 148 & 13 & 95 & 40 & 0.001 \\
\hline 1-29 Gy & 82 & 8 & 52 & 22 & 0.05 \\
\hline$\geq 30 \mathrm{~Gy}$ & 66 & 5 & 43 & 18 & 0.03 \\
\hline Chest/neck irradiation ${ }^{\mathrm{b}}$ & 90 & 13 & 58 & 19 & 0.85 \\
\hline Abdominal irradiation ${ }^{\mathrm{b}}$ & 80 & 15 & 47 & 18 & 0.65 \\
\hline Total body irradiation ${ }^{\mathrm{b}}$ & 22 & 8 & 12 & 2 & $0.017^{\mathrm{c}}$ \\
\hline Duration of treatment (years) ${ }^{\mathrm{a}}$ & $1.3(0.1-4.9)$ & $1.4(0.2-4.9)$ & $1.2(0.1-4.2)$ & $1.5(0.1-4.6)$ & 0.95 \\
\hline Underweight at diagnosis & $107 / 344^{\mathrm{d}}$ & $28 / 48^{\mathrm{e}}$ & $69 / 229^{f}$ & $10 / 67^{\mathrm{g}}$ & $<0.001$ \\
\hline Overweight at diagnosis & $19 / 344^{\mathrm{d}}$ & $1 / 48^{\mathrm{e}}$ & $3 / 229^{f}$ & $15 / 67^{\mathrm{g}}$ & 0.002 \\
\hline
\end{tabular}

$B M I$ body mass index, $F H$ final height

${ }^{\mathrm{a}}$ Median (range)

${ }^{\mathrm{b}}$ Numbers

${ }^{\mathrm{c}}$ Fisher's exact test

${ }^{\mathrm{d}}$ Missing data at diagnosis $n=33$

${ }^{\mathrm{e}}$ Missing data at diagnosis $n=5$

${ }^{\mathrm{f}}$ Missing data at diagnosis $n=22$

${ }^{\mathrm{g}}$ Missing data at diagnosis $n=6$

\section{Discussion}

The current study provides cross-sectional and longitudinal BMI estimations as well as an estimation of annual BMI increase in childhood cancer survivors who are at risk for treatment-related cardiac and vascular late effects.

We found no difference in overweight between the entire group of survivors and the reference population, whereas the prevalence of underweight had increased. Within the study population, survivors with overweight at $\mathrm{FH}$ had a higher prevalence of overweight at diagnosis. In the adjusted models (including overweight at diagnosis), overweight at $\mathrm{FH}$ was associated with CRT, especially if the CRT dose was 30 Gy or more. Survivors who received CRT $\geq 30$ Gy also had a higher rate of BMI increase after completion of treatment until FH, which is in accordance with the higher prevalence of overweight at FH in these subjects. The association of overweight and CRT is well known, has been described by several authors, and has been suggested to be the result of neuroendocrine impairment [1, 3, 22, 23]. However, only a limited number of studies are available on BMI evaluations at several time points during and/or after childhood cancer 
Table 2 Relationship between underweight/overweight at $\mathrm{FH}$ and treatment variables; logistic regression $^{\mathrm{a}}$
${ }^{a}$ Adjusted for age, underweight and overweight at diagnosis, gender and age at $\mathrm{FH}$, and duration of treatment

FH final height; $O R$ odds ratio; $C I$ confidence interval; $C R T$ cranial/craniospinal irradiation
Underweight at FH OR $(95 \%$ CI)

Overweight at FH OR $(95 \%$ CI $)$

Anthracyclines
Cumulative dose by $100 \mathrm{mg} / \mathrm{m}^{2}$
Cumulative dose $>300 \mathrm{mg} / \mathrm{m}^{2}$
Platinum
CRT
0 Gy (reference)
$1-29$ Gy
$\geq 30$ Gy

$1.09(0.51-2.29)$

$0.67(0.34-1.31)$

$1.27(1.04-1.56)$

$0.94(0.77-1.16)$

$2.84(1.33-6.06)$

$0.84(0.37-1.94)$

$1.40(0.47-4.15)$

$0.86(0.25-2.90)$

$0.34(0.15-0.75)$

$2.23(1.17-4.26)$

1

$0.32(0.12-0.85)$

1

$0.37(0.12-1.13)$

$1.98(0.90-4.39)$

$2.55(1.12-5.80)$

Total body irradiation (TBI)

$3.28(1.11-9.68)$

$0.57(0.12-2.74)$

$2.27(1.13-4.55)$

$0.78(0.16-3.82)$

$1.16(0.48-2.81)$ treatment [2, 3, 17, 24, 25], while studies assessing the rate of BMI increase are even scarcer [17, 23]. Razzouk et al. studied the rate of BMI increase in survivors of a haematological malignancy and found that overweight at diagnosis was the most significant predictor of overweight at adult height, while no significantly different BMI increase over time was found among patients with or without CRT [17]. Others found that survivors who received CRT, especially if 10 Gy or more, had a significantly greater net increase in BMI per year in comparison with sibling controls; however, they did not adjust for BMI at diagnosis [23]. In the current study, we found that survivors who received CRT, especially if $\geq 30 \mathrm{~Gy}$, had a greater annual BMI increase, even after adjustment for overweight at diagnosis. Various possible underlying mechanisms have been described for overweight in survivors [26]. One possible hypothesis is that overweight may be the result of a disturbed energy balance during and after childhood cancer treatment $[27,28]$. In survivors who received CRT, this might be caused by irradiation damage to the hypothalamicpituitary axis [29, 30]. The hypothesis of a disturbed energy balance is supported by our finding of a higher BMI already evident at completion of treatment in survivors who received CRT, suggesting that the development of an abnormal body composition after CRT may start already during treatment and continue after discontinuation of treatment. We did not find an association with gender, which is not in accordance with some other studies [17, 20].

Although our primary objective was to study overweight/ obesity in a population at high risk for cardiovascular disorders, we found an increased prevalence of underweight compared to the reference population. Underweight is a less well-known late effect in childhood cancer survivors. In our study, underweight at diagnosis was an important predictor of underweight at FH. After adjustment for underweight at diagnosis, we found that underweight at $\mathrm{FH}$ was associated
Table 3 Association between annual BMI increase and treatment by multilevel analysis ${ }^{\mathrm{a}}$

Dependent variables: BMI at end of treatment and annual BMI increase post-treatment; independent variables: anthracyclines, platinum, CRT, TBI

$B M I$ body mass index; $C I$ confidence interval; $C R T$ cranial/craniospinal irradiation; TBI total body irradiation

a Adjusted for age, underweight, and overweight at diagnosis, and for gender

\begin{tabular}{|c|c|c|c|c|c|}
\hline & & \multicolumn{2}{|c|}{ BMI at end of treatment $\mathrm{kg} / \mathrm{m}^{2}$} & \multicolumn{2}{|c|}{ Annual BMI increase $\left(\mathrm{kg} / \mathrm{m}^{2} /\right.$ year $)$} \\
\hline & & Estimate $(95 \% \mathrm{CI})$ & $p$ value & Estimate $(95 \% \mathrm{CI})$ & p-value \\
\hline \multicolumn{2}{|l|}{ Intercept } & $13.08(1227-13.88)$ & $<0.001$ & $0.47(0.34-0.60)$ & $<0.001$ \\
\hline \multirow[t]{2}{*}{ Anthracyclines } & No & 0 & & 0 & \\
\hline & Yes & $0.07(-0.44-0.59)$ & 0.78 & $-0.08(-0.16-0.003)$ & 0.06 \\
\hline \multicolumn{2}{|c|}{ Cumulative dose by $100 \mathrm{mg} / \mathrm{m}^{2}$} & $-0.07(-0.23-0.09)$ & 0.38 & $-0.03(-0.05-0.0005)$ & 0.046 \\
\hline \multirow[t]{2}{*}{ Platinum } & No & 0 & & 0 & \\
\hline & Yes & $0.04(-0.93-1.02)$ & 0.93 & $0.05(-0.11-0.21)$ & 0.53 \\
\hline \multirow[t]{4}{*}{ CRT } & No & 0 & & 0 & \\
\hline & Yes & $0.59(0.09-1.09)$ & 0.02 & $0.07(-0.01-0.15)$ & 0.09 \\
\hline & $1-29$ Gy & $0.91(0.30-1.52)$ & 0.004 & $0.01(-0.09-0.11)$ & 0.83 \\
\hline & $\geq 30$ Gy & $0.19(-0.47-0.86)$ & 0.57 & $0.15(0.04-0.25)$ & 0.008 \\
\hline \multirow[t]{2}{*}{ TBI } & No & 0 & & 0 & \\
\hline & Yes & $-0.96(-1.98-0.05)$ & 0.06 & $0.01(-0.15-0.17)$ & 0.88 \\
\hline
\end{tabular}


with a higher cumulative anthracycline dose, especially above $300 \mathrm{mg} / \mathrm{m}^{2}$. These results are in accordance with the crosssectional study by Meacham et al., who also observed a higher prevalence of underweight in survivors compared with a national reference population ( $6 \%$ vs. $3 \%)$. In their study, underweight was associated with previous treatment with anthracyclines and alkylating agents (in males and females), abdominal RT (in males), and TBI (in females) [20]. They stated that the majority of underweight survivors $(>70 \%)$ had an underlying problem (that is, adverse health status, a major medical condition, and/or smoking) that contributed to their underweight [20]. However, in that study, the association of underweight with BMI at completion of treatment was not evaluated. In our study, we found that BMI at completion of treatment was not associated with anthracyclines, but that, in those who were treated with a higher cumulative anthracycline dose, annual BMI increase after completion of treatment was lower compared to those who received less or no anthracyclines. This resulted in a 1.27-fold higher risk of underweight at $\mathrm{FH}$ per $100 \mathrm{mg} / \mathrm{m}^{2}$ increase in cumulative dose of anthracyclines, suggesting that anthracyclines play a role in the development of underweight in long-term CCS. However, the underlying mechanism remains unclear.

In the general population, underweight, like overweight, is associated with increased morbidity. Both overweight and underweight have been described in association with increased all-cause mortality [31, 32]. Calle et al. described the association between BMI and the risk of death in a cohort of more than one million US adults. They found a J-shaped curve for risk of all-cause death, including cardiovascular death; a high BMI $\left(\geq 25 \mathrm{~kg} / \mathrm{m}^{2}\right)$ was the most predictive of death, but the risk also increased in persons with a $\mathrm{BMI}<20.5 \mathrm{~kg} / \mathrm{m}^{2}$ [31].

It is generally assumed that in the general population, the mortality and morbidity due to cardiovascular disease can be reduced by the prevention and/or treatment of cardiovascular risk factors, such as overweight and probably also underweight. Results from the current study suggest that, if applied to childhood cancer survivors, the type of cancer treatment may guide the timing for initiation of prevention strategies. By combining the results of cross-sectional and longitudinal BMI calculations, we were able to identify the time course of the development of overweight or underweight in the studied cohort of childhood cancer survivors. By doing so, the timing of interventional strategies for survivors at risk may be facilitated. This is a major strength of our study. In survivors with CRT, who are already at risk for an abnormal BMI during cancer treatment, early awareness, prevention, and timely life-style interventions are highly warranted. On the other hand, anthracycline-treated survivors, in particular those with higher cumulative doses are at risk for underweight after termination of treatment and therefore need careful monitoring of nutritional status, caloric intake, and caloric expenditure during follow-up.

Our study has several limitations. Due to the study design, there was a selected group of patients who made up a subset of the covering study on cardiovascular toxicity. Also related to the study design and the inclusion criteria, we examined only two chemotherapy categories, anthracycline-based and platinum-based. Therefore an unbiased analysis with respect to other agents was troublesome and the multicollinearity of treatment schedules precluded discrimination of the independent effects of other chemotherapeutic agents. Another limitation is the heterogeneity of the cohort. To overcome this, we used regression analyses to adjust for possibly confounding variables. In this heterogeneous group we found no association of BMI status and additional variables that could impact the development of underweight or overweight in CCS, such as treatment intensity, chronic health conditions (e.g. renal dysfunction), cardiovascular disease, and family history of obesity/overweight.

Finally, due to the retrospective design of the study, it was not possible to compare the annual increase in BMI with that of healthy controls.

In conclusion, overweight and underweight at diagnosis are important predictors of weight outcome at FH. Moreover, even after adjustment for these variables, survivors who received CRT had a higher BMI at termination of cancer treatment and at $\mathrm{FH}$, and survivors with higher anthracycline doses had a lower BMI increase after termination of treatment, which was reflected in more underweight at FH. Health care providers and patients need to be aware of the association of CRT with overweight and of anthracyclines with underweight in order to enable timely life-style changes.

Acknowledgements This study was supported by a grant from the foundation 'The Quality of Life Gala (2003)'.

Disclosure statement There are no conflicts of interest.

Open Access This article is distributed under the terms of the Creative Commons Attribution Noncommercial License which permits any noncommercial use, distribution, and reproduction in any medium, provided the original author(s) and source are credited.

\section{References}

1. Oeffinger KC, Mertens AC, Sklar CA, Yasui Y, Fears T, Stovall M, Vik TA, Inskip PD, Robison LL, Childhood Cancer Survivor Study (2003) Obesity in adult survivors of childhood acute lymphoblastic leukemia: a report from the Childhood Cancer Survivor Study. J Clin Oncol 21:1359-1365 
2. Dalton VK, Rue M, Silverman LB, Gelber RD, Asselin BL, Barr RD, Clavell LA, Hurwitz CA, Moghrabi A, Samson Y, Schorin M, Tarbell NJ, Sallan SE, Cohen LE (2003) Height and weight in children treated for acute lymphoblastic leukemia: relationship to CNS treatment. J Clin Oncol 21:2953-2960

3. Sklar CA, Mertens AC, Walter A, Mitchell D, Nesbit ME, O'Leary M, Hutchinson R, Meadows AT, Robison LL (2000) Changes in body mass index and prevalence of overweight in survivors of childhood acute lymphoblastic leukemia: role of cranial irradiation. Med Pediatr Oncol 35:91-95

4. Bowers DC, Liu Y, Leisenring W, McNeil E, Stovall M, Gurney JG, Robison LL, Packer RJ, Oeffinger KC (2006) Late-occurring stroke among long-term survivors of childhood leukemia and brain tumors: a report from the Childhood Cancer Survivor Study. J Clin Oncol 24:5277-5282

5. Brouwer CA, Gietema JA, van den Berg MP, Bink-Boelkens MT, Elzenga NJ, Haaksma J, Kamps WA, Vonk JM, de Vries EG, Postma A (2006) Long-term cardiac follow-up in survivors of a malignant bone tumour. Ann Oncol 17:1586-1591

6. Chow AY, Chin C, Dahl G, Rosenthal DN (2006) Anthracyclines cause endothelial injury in pediatric cancer patients: a pilot study. J Clin Oncol 24:925-928

7. Lipshultz SE, Lipsitz SR, Sallan SE, Dalton VM, Mone SM, Gelber RD, Colan SD (2005) Chronic progressive cardiac dysfunction years after doxorubicin therapy for childhood acute lymphoblastic leukemia. J Clin Oncol 23:2629-2636

8. Adams MJ, Lipsitz SR, Colan SD, Tarbell NJ, Treves ST, Diller L, Greenbaum N, Mauch P, Lipshultz SE (2004) Cardiovascular status in long-term survivors of Hodgkin's disease treated with chest radiotherapy. J Clin Oncol 22:3139-3148

9. Van den Belt-Dusebout AW, de Wit R, Gietema JA, Horenblas S, Louwman MW, Ribot JG, Hoekstra HJ, Ouwens GM, Aleman BM, van Leeuwen FE (2007) Treatment-specific risks of second malignancies and cardiovascular disease in 5-year survivors of testicular cancer. J Clin Oncol 25:4370-4378

10. Huddart RA, Norman A, Shahidi M, Horwich A, Coward D, Nicholls J, Dearnaley DP (2003) Cardiovascular disease as a longterm complication of treatment for testicular cancer. J Clin Oncol 21:1513-1523

11. Hopewell JW, Campling D, Calvo W, Reinhold HS, Wilkinson JH, Yeung TK (1986) Vascular irradiation: its cellular basis and likely consequences. Br J Cancer 53(Suppl VII):181-191

12. O'Connor MM, Mayberg MR (2000) Effects of radiation on cerebral vasculature: a review. Neurosurgery 46:138-149

13. Morris B, Partap S, Yeom K, Gibbs IC, Fisher PG, King AA (2009) Cerebrovascular disease in childhood cancer survivors: a children's oncology group report. Neurology 73:1906-1913

14. Oeffinger KC, Adams-Huet B, Victor RG, Church TS, Snell PG, Dunn AL, Eshelman-Kent DA, Ross R, Janiszewski PM, Turoff AJ, Brooks S, Vega GL (2009) Insulin resistance and risk factors for cardiovascular disease in young adult survivors of childhood acute lymphoblastic leukemia. J Clin Oncol 27:3698-3704

15. Cole TJ, Bellizzi MC, Flegal KM, Dietz WH (2000) Establishing a standard definition for child overweight and obesity worldwide: international survey. BMJ 320:1240-1243

16. Van Buuren S (2004) Body-mass index cut-off values for underweight in Dutch children. Ned Tijdschr Geneeskd 148:1967-1972

17. Razzouk BI, Rose SR, Hongeng S, Wallace D, Smeltzer MP, Zacher M, Pui CH, Hudson MM (2007) Obesity in survivors of childhood acute lymphoblastic leukemia and lymphoma. J Clin Oncol 25:1183-1189

18. Boezen HM, Vonk JM, van Aalderen WM, Brand PL, Gerritsen J, Schouten JP, Boersma ER (2000) Perinatal predictors of respiratory symptoms and lung function at a young adult age. Eur Respir $\mathrm{J}$ 20:383-390

19. Vonk JM, Boezen HM, Postma DS, Schouten JP, van Aalderen WM, Boersma ER (2004) Perinatal risk factors for bronchial hyperresponsiveness and atopy after a follow-up of 20 years. J Allergy Clin Immunol 114:270-276

20. Meacham LR, Gurney JG, Mertens AC, Ness KK, Sklar CA, Robison LL, Oeffinger KC (2005) Body mass index in long-term adult survivors of childhood cancer: a report of the Childhood Cancer Survivor Study. Cancer 103:1730-1739

21. Laird NM, Ware JH (1982) Random-effects models for longitudinal data. Biometrics 38:963-974

22. Van Beek RD, de Muinck Keizer-Schrama SM, HakvoortCammel FG, van der Sluis IM, Krenning EP, Pieters R, van den Heuvel-Eibrink MM (2006) No difference between prednisolone and dexamethasone treatment in bone mineral density and growth in long term survivors of childhood acute lymphoblastic leukemia. Pediatr Blood Cancer 46:88-93

23. Garmey EG, Liu Q, Sklar CA et al (2008) Obesity in adult survivors of childhood acute lymphoblastic leukemia: a follow-up report from the Childhood Cancer Survivor Study. J Clin Oncol 26:4639-4645

24. Marinovic D, Dorgeret S, Lescoeur B, Alberti C, Noel M, Czernichow P, Sebag G, Vilmer E, Léger J (2005) Improvement in bone mineral density and body composition in survivors of childhood acute lymphoblastic leukemia: a 1-year prospective study. Pediatrics 116:e102-e108

25. Davies JH, Evans BA, Jones E, Evans WD, Jenney ME, Gregory JW (2004) Osteopenia, excess adiposity and hyperleptinaemia during 2 years of treatment for childhood acute lymphoblastic leukaemia without cranial irradiation. Clin Endocrinol (Oxf) 60:358-365

26. Brouwer CA, Gietema JA, Kamps WA, de Vries EG, Postma A (2007) Changes in body composition after childhood cancer treatment: impact on future health status - a review. Crit Rev Oncol Hematol 63:32-46

27. Mayer EI, Reuter M, Dopfer RE, Ranke MB (2000) Energy expenditure, energy intake and prevalence of obesity after therapy for acute lymphoblastic leukemia during childhood. Horm Res 53:193-199

28. Reilly JJ, Brougham M, Montgomery C, Richardson F, Kelly A, Gibson BE (2001) Effect of glucocorticoid therapy on energy intake in children treated for acute lymphoblastic leukemia. J Clin Endocrinol Metab 86:3742-3745

29. Lustig RH, Post SR, Srivannaboon K, Rose SR, Danish RK, Burghen GA, Xiong X, Wu S, Merchant TE (2003) Risk factors for the development of obesity in children surviving brain tumors. J Clin Endocrinol Metab 88:611-616

30. Warner JT, Bell W, Webb DK, Gregory JW (1997) Relationship between cardiopulmonary response to exercise and adiposity in survivors of childhood malignancy. Arch Dis Child 76:298-303

31. Calle EE, Thun MJ, Petrelli JM, Rodriguez C, Heath CW Jr (1999) Body-mass index and mortality in a prospective cohort of U.S. adults. N Engl J Med 341:1097-1105

32. Flegal KM, Graubard BI, Williamson DF, Gail MH (2007) Causespecific excess deaths associated with underweight, overweight, and obesity. JAMA 298:2028-2037 